\title{
Utilities’ Business Models for Renewable Energy: Evidence from Germany
}

\author{
Mario Richter \\ Centre for Sustainability Management (CSM), Leuphana University of Lüneburg, Lüneburg, Germany \\ Tel: +49 17626392486, Fax: +49 41316772186,E-mail: Mario.Richter@uni.leuphana.de
}

\begin{abstract}
This study on German utilities' business models for renewable energies provides new insights into the thinking of Germany's leading utilities about future business models. Two generic business models are derived from the literature and are subsequently analyzed based on a series of in-depth interviews. A core result is that utilities clearly favor large scale projects over small scale projects on the customer-side. This result can be explained with the return potential and renewable energy portfolio standards. Contradictory to the existing literature, German utilities do not see electricity generation on the customer-side as threat to their business model. Instead, they develop very different approaches for large scale projects. It can be concluded that utility engagement in customer-side business models will remain limited in Germany, whereas large scale projects are seen as a promising future business model. The analysis from a business model perspective also shows that both business models, for small scale as well as for large scale projects, still offer room for innovation. Hence, business model innovation can help utilities to create and capture more value in the energy transition.
\end{abstract}

Keywords: Renewable Energy, Business Model, Utility, Energy Transition

\section{Introduction}

About $82 \%$ of the world's electric energy supply is either based on fossil fuels like coal, gas, and oil, or nuclear energy [1]. A key measure to fight climate change and resource depletion is the transformation of the electric power sector towards a more sustainable form of energy production based on renewable energies [2]. It is expected that the transformation will change the structure of the industry and the electric utilities as its largest actors. Several studies on this issue indicate that there will be little room for the utilities' business model in its present form [3][4][5].

The present study contributes to the discussion about utilities' business models for renewable energies by providing insight into the thinking of Germany's leading utilities. The traditional utility business model is delivery of electricity generated from large centralized power plants to the end customer. Since renewable energies are more decentralized, some authors argue that the increasing share of renewable energy generation by customers is a threat to the traditional utility business model, because it leads to decreasing electricity demand and, consequently, erosion of revenues [3][4][6][7]. Following this argument, finding new approaches to serve customers with less and cleaner energy requires a fundamental rethinking of how utilities produce, transmit, and sell electricity. Therefore the research question of this work is: How do German utilities shape their business models for renewable energies?

Two generic business models are derived from the literature and are subsequently analyzed on the basis of in-depth interviews with managers of German utilities. The preliminary results show that utilities clearly favor large scale projects and do not expect small scale renewable energy projects on the customer-side to be of great importance. This preference can be explained with transaction costs, economies of scale, and ambitious renewable portfolio standards. 
The study is organized as follows. Section 2 introduces the business model concept and provides a literature review on utilities' business models for renewable energies. Section 3 describes the methodology, section 4 displays the results. The essay finishes with a discussion in section 5 and a conclusion in section 6 .

\section{Literature Review}

\subsection{The Business Model as a Tool for Analysis and Management}

The business model is a valuable new tool for analysis and management in research and practice [8]. In terms of analysis, the concept enables the examination and comparison of companies and markets in a structured way. Using the business model as a classifying device helps to expand the understanding of business phenomena by building generic categories and the development of ideal types [9]. As a management tool, the business model helps managers to design, implement, operate, change, and control their business [10]. In this context, business models can function as "recipes" or "blueprints" that are ready for copying or variation and innovation [9]. Furthermore, thinking in business model terms also enable managers to react to external factors and influences quicker and more appropriately.

Despite the increasing importance of the business model concept in the academic literature there is no generally accepted definition. A review of the literature shows that many business model definitions are comprised of four basic elements [11][12][13]. The value proposition describes the products and services that are offered to the customers [11][14]. The customer interface describes the overall interaction with the customer [15]. The infrastructure comprises the companies' activities and assets required to create the value proposition, thus the internal organization of the value creation process [11]. The revenue model represents all revenues and costs associated with selling the value proposition [13][14][15].

Table 1. The Business Model Conceptualization [12][15]

\begin{tabular}{ll}
\hline Business Model Pillar & Description \\
\hline Value Proposition & $\begin{array}{l}\text { The value proposition describes the bundle of products and } \\
\text { services that create value for the customer and allows the } \\
\text { company to earn revenues. }\end{array}$ \\
Customer Interface & $\begin{array}{l}\text { Customer interface comprises the whole contact with the } \\
\text { customer. } \\
\text { Infrastructure }\end{array}$ \\
The infrastructure describes the architecture of the \\
company's value creation. \\
The revenue model describes the relationship between costs \\
to produce the value proposition and the revenues that are \\
generated by offering the value proposition the customers.
\end{tabular}

The conceptualization of the business model displayed above refers to the terminology of Alexander Osterwalder and Yves Pigneur [12][15]. The authors define: "a business model describes the rationale of how an organization creates, delivers, and captures value" [15]. This conceptualization offers some advantages: first, it is easy to apply and has been extensively tested in practice. Second, the terminology is widely used and accepted, and third, it has already been successfully applied to the field of renewable energies [16]. 


\subsection{Utilities' Business Models for Renewable Energy}

The renewable energy business model currently most widespread in Germany (as well as in the United States and Europe) functions as follows: the customer or a private investor owns and controls a renewable energy system, while the utility provides grid connection and is obliged to purchase the electricity. The costs for these services can be passed on to the consumer, but no return may be earned from this service [6]. The utility remains passive and just complies with the regulation. In this model, an increasing share of renewable energies is a threat to utilities, because utilities lose market share and revenues.

Many studies on utilities' business models have focused on this threat from customer-side renewable energy systems. Authors of these studies argue that an increasing share of renewable energy systems owned and operated by customers leads to decreasing electricity demand and consequently erosion of revenues [3][4][5][6][7]. Hence, the question for utilities is how to benefit from increasing customer-side generation. The literature provides different ideas on how an utility business model for customer-side renewable energy could look like [6][7]. For example, Frantzis et al. observed that the most promising approach for utilities is to own and operate the renewable energy system, because a return on the assets can be earned [3][6]. Referring to these studies a generic business model for customer-side renewable energy can be characterized as follows:

Customer-side renewable energy business model: In this business model the renewable energy systems is located on the property of the customer. Possible technologies are photovoltaic, solar thermal hot water, CHP micro power, geothermal heat pumps, and micro wind turbines. The size of the systems usually ranges between a few kilowatts and about $1 \mathrm{MW}$. The value proposition offered by the utility can range from simple consulting services to a full-services package including financing, ownership and operation of the asset [3][4][5]. Utility financing and ownership of customer-side assets intensifies the customer relationship and can provide access to new customer segments, of customers who otherwise could not afford installation of renewable energy systems [4]. As far as the utilities' architecture of value creation is concerned, a management approach for small scale projects is needed [7]. The revenues for the utility come from return on the assets and charge for services, while costs arise from administration, installation and operation of the systems [6].

Another option for utilities is to invest in large scale renewable energy projects. This approach is represented by the second generic business model:

Utility-side renewable energy business model: The projects are larger than customer-side projects and range from one to some hundred megawatts. Typical technologies are on- and offshore wind farms, large scale photovoltaic projects, biomass power plants, and solar thermal power plants [4][6][7]. The value proposition in this business model is bulk generation of electricity that is fed into the grid [6]. Therefore, the customer interface consists of power purchase agreements on a business to business level, rather than a relationship to the end-customer. As far as the infrastructure is concerned, these projects are much more similar to traditional centralized power plants than the customer-side business model. They are much closer to the utilities' core competency of asset management and operation [6][7]. Costs arise from construction and operation of the 
energy project, while revenues come from regulated feed-in tariffs for electricity or tax- or investment credits.

The two generic business models are "ideal types" and represent the two sides of a spectrum [9]. Of course variations are possible. Both business models will be subsequently analyzed in the context of the German utility sector to identify challenges and potential and eventually derive evidence for future trends.

\section{Methodology}

The present study is based on an explorative qualitative research design, because there is no empirical evidence on this issue from the German market yet. The data is derived from a series of semi-structured interviews with managers of German utilities. The sample selection focuses on Germany, because the country is considered one of the world's leading markets for renewable energies. Of some 800 utilities of very different size and scope of activity four categories were identified by theoretical sampling [18]. Since the selected qualitative approach does not allow to derive statistically relevant information, the innovation leaders in every of the four category were selected - following the idea of extreme cases by Yin [19]. The selected companies were identified through internet research and consultation of industry experts from utilities, industry associations, and consulting.

Table 2. Categories of German Utilities

\begin{tabular}{lcc}
\hline Category & Revenues in million $€$ & Size of Category \\
\hline 1. Multinational utilities & $>10.000$ & 4 \\
2. Regional utilities & $10.000-1.000$ & 10 \\
3. Large Local Utilities & $999-100$ & $\sim 80$ \\
4. Small Local Utilities & $100-0$ & $\sim 700$ \\
\hline
\end{tabular}

To date, 15 interviews have been conducted, with managers from 11 utilities. In some cases two interviews per utility were helpful when the responsibility for customer-side and utilityside business models lay in different departments. It is planned to conduct 9 more interviews in the coming weeks. Therefore, the results of this essay are preliminary. So far, the following utilities are included in this study: E.on, Vattenfall, EnbW, RWE, Stadtwerke München, EWE, Mainova, HEAG Südhessische Energie, Stadtwerke Aachen, Stadtwerke Karlsruhe, and Hamburg Energie. The interviewees are directors or managers, mainly from business development departments. The interviews are partly conducted in person and partly via telephone. Length of the conversations varies between 45 and 90 minutes. The interviews are recorded on tape and subsequently transferred into a written protocol. The protocols were analyzed following the conceptual business model components presented above.

\section{Preliminary Results}

The results show that the interviewed utilities have very different opinions on the future role of customer-side renewable energies. Whereas the future development in this market is not at all clear today, the business model for utility-side projects is clear and plays a significant role in utilities current activities. The reasons for this result can be explained by analyzing the two generic business models following the four pillar structure (see section 2.1). 


\subsection{Customer-Side Renewable Energy Generation}

The interviews show that contrary to the argumentation in the literature, 9 out of 11 interviewed utility managers do not see customer-side generation as a threat to the current utility business model. They mainly see customer-side renewable energy as a niche market without much revenue potential for utilities.

\subsubsection{Value Proposition}

Five of the 11 interviewed companies offer customer-side renewable energy products or services. For example they support their customers to install solar PV systems or micro CHP systems. But in practice, none of them is actively promoting these offers, because none of the offerings is actually profitable. In practice, it is far from clear what utilities intend to offer to their customer. Only 2 out of 15 interviewees expect customer generation to become a severe threat to the current value proposition. The rest does not see a profitable market and thus no urgent need to develop new value propositions in this field. The utilities that actively try to develop new value propositions admit that they severely struggle to find economically sustainable business models.

\subsubsection{Customer Interface}

Renewable energy is considered to have positive effects on the customer relationship by all interviewees. The existing products and services for end-customers are designed to increase the individual customer relationship and secure long term gas and electricity delivery. Projects like installation of solar systems on schools or public buildings are used to demonstrate community involvement.

\subsubsection{Infrastructure}

Infrastructure for customer-side business models exists on a very small scale, because the projects are not profitable yet. Activities are seen as "pilot project" and are organized in separate firms to have better control over costs and revenues. The main purpose is testing the market. New infrastructure is hardly built up before the value proposition and revenue model are clear. One approach to be active without the need to build up own infrastructure is to establish partnerships with local companies that provide installation and other services.

\subsubsection{Revenue Model}

All interviewed utilities' that have some sort of some customer-side renewable energy business model struggle to earn sufficient returns. There is no economic sustainable revenue model in the market yet. Customer-side projects are too small and too fragmented to be able to contribute significantly to the earnings of the company. An economically sustainable revenue model is the key to unlock the market of customer-side renewable energies for utilities.

\subsection{Utility-side Renewable Energy Generation}

The interviewed utilities are currently investing billions of Euros into utility-side renewable energy projects. Most attractive technologies are on- and offshore wind energy as well as biomass and biogas. Solar energy only plays a minor role in investment budgets, since this technology only contributes a small share to the electricity generation capacity. 


\subsubsection{Value Proposition}

The interviewees do not see the traditional value proposition under pressure by increasing shares of large scale renewable energy projects. On the contrary, most managers see an additional value that can be offered to the customer in the form of green electricity tariffs.

\subsubsection{Customer Interface}

The interviewees perceive customers as increasingly critical towards utilities. In this context utilities try to strengthen their customer relationship by positioning themselves as environmentally friendly. In addition, the regional and local utilities use renewable energies to demonstrate community involvement. On the other hand, utilities face stakeholder opposition towards new large scale renewable energy projects. One approach to ease such a conflict is offering participation in the project. This way utilities and customer become joint investors. Overall, the utilities see the customer interface positively affected by renewable energies.

\subsubsection{Infrastructure}

Utilities are currently investing massively in projects to create their own renewable generation infrastructure. In this context they also develop the corporate infrastructure to operate and manage the renewable energy assets. The main question in this context is in which steps of the renewable energy project value chain the utility should become active. Larger utilities tend towards integration of project development and maintenance services into their business model. This way they enhance the value creation in the project and are able to earn a higher overall return with the energy project. Smaller utilities rely much more on external service providers for project development and maintenance service, because it is too costly to hire skilled personnel for a small generation infrastructure. While "blueprints" for utility-side revenue models are available in the market, it seems as if the project value chain offers room for business model innovation for all types of utilities.

\subsubsection{Revenue Model}

Investment decisions for utility-side renewable energy projects are usually based on well defined return expectations. Therefore, the revenue model is the key to the decision whether a renewable energy project is realized or not. Although renewable energy projects provide lower returns than conventional power projects, they include less risk which makes them attractive to utilities from a financial viewpoint as well. While the interviewed multinational utilities point out the role of business model innovation to increase revenues and decrease costs, the interviewed regional and local utilities emphasize the need to also include community aspects in their decisions. The optimization of the value chain according to the utilities competencies offers large potential to increase earnings.

\section{Discussion}

The present study shows that the interviewed utilities mainly do not perceive revenue erosion by customer-side electricity generation as a threat to their current business model. Only two interviewees speak of a severe threat. The utilities clearly favor large scale utility-side projects over customer-side projects, as the former offer more attractive returns and allow to reach renewable portfolio standards more quickly. The higher returns were identified to be mainly a consequence of transaction costs, which e.g. comprise project development cost, such as costs for planning, permission, and administration. These costs account for a significant portion of the overall costs and do not rise in proportion with the size of the 
project. Also larger projects allow favorable cost structures for asset management as well as operation and maintenance. Therefore, larger projects have comparatively lower project development costs [20]. Besides, for the same reason larger projects make reaching a certain renewable portfolio ratio in a given time easier and cheaper. Furthermore, the analysis from the business model perspective revealed that utility-side projects offer a series of advantages: they do not make new value propositions necessary, the customer interface is positively affected, and revenue potential is clearer than is seen with customer-side projects. Customerside renewable energy was not considered an interesting future market by most interviewed utilities. Some of the utilities have undertaken first steps to build customer-side business models, but activities are at a very early stage and budgets are small. The analysis reveals that many questions about the value proposition, the infrastructure, and the revenue model are unanswered. The main challenge is to reach profitability of the revenue model.

Many authors on utilities' business models for renewable energy argue that customer-side electricity generation from renewable energies requires utilities to develop new value propositions to combat loss of market share and revenue erosion [3][4][7]. The analysis in this study shows that most utilities focus on large scale projects and do not see customer-side renewable energy as a threat to their business. From a business model perspective it makes sense to invest in large scale projects, because business model templates are available and returns are higher. Furthermore, large scale projects make it easier to reach the renewable portfolio standards. From these findings it can be concluded, that utility engagement in customer-side business model for renewable energy will remain limited in Germany, whereas large scale renewable energy projects are a promising future business model for utilities.

The findings are subject to some limitations. The method of conducting qualitative semistructured interviews has proven well suited to gain a first insight into utility thinking, but it does not allow drawing any rigorous generalizations. Furthermore, the high level approach in the interviews creates the danger of over-simplification. The same is true for the approach to analyze two generic business models, which cannot cover all details of real world utility business models. Furthermore, business models are highly dependent on the regulatory framework, so the results might not easily be transferred to other markets [6]. Also, the data collection is not fully completed yet, therefore, the results of this article are preliminary.

The research raises a series of new questions on how utilities can improve their business models. Further research should focus on both utility-side business models as well as customer-side business models in more detail. The former still offer room for revenue improvement when further steps in the value chain are integrated or suitable collaborations are installed. The latter represents a market which is mainly untapped by utilities to date, due to comparably low return expectations. Research on new business model designs might help to overcome this hurdle and open a large new market for utilities.

\section{Conclusion}

The present study shows that utilities focus on large scale utility-side project rather than on customer-side projects. The analysis showed that both business models offer much room for innovation. Consequently, utilities should intensify their thinking about business models to increase their potential to create and capture value from the energy transformation. Furthermore, policy-makers should pay close attention to the developments in this field in order to shape the framework for a truly sustainable energy future. 


\section{References}

[1] International Energy Agency (IEA), Key World Energy Statistics, 2009.

[2] Intergovernmental Panel on Climate Change (IPCC), IPPC fourth Assessment Synthesis Report, Cambridge University Press, 2007.

[3] L. Frantzis, S. Graham, R. Katofsky, H. Sawyer, Photovoltaic Business Models, National Renewable Energy Laboratory, 2008.

[4] R. Duncan, Renewable Energy and the Utility: The Next 20 Years, Renewable Energy World 2 (3), 2010.

[5] F. Klose, M. Kofluk, S. Lehrke, H. Rubner, Toward a Distributed-Power World, The Boston Consulting Group Report, 2010.

[6] J. Nimmons, M. Taylor, Utility Solar Business Models: Emerging Utility Strategies \& Innovation, SEPA Report, 2008.

[7] J. Schoettl, L. Lehmann-Ortega, Photovoltaic Business Models: Threat or Opportunity for Utilities?, R. Wüstenhagen, R. Wuebker (Eds.), Handbook of Research on Energy Entrepreneurship, Edward Elgar Publishing Ltd., 2010.

[8] C. Zott, R. Amit, The Fit between Product Market Strategy and Business Model: Implications for Firm Performance, Strategic Management Journal 29, 2008, pp. 1-26.

[9] C. Baden-Fuller, M. Morgan, Business Models as Models, Long Range Planning 43, 2010, pp. 156-171.

[10]B.W. Wirtz, O. Schilke, S. Ulrich, Strategic Development of Business Models, Long Range Planning 43, 2010, pp. 272-290.

[11] M. Johnson, Seizing the white space. Business model innovation for growth and renewal, Harvard Business Press, 2010.

[12]A. Osterwalder, The Business Model Ontology, Diss. at University of Lausanne, 2004.

[13]P. Stähler, Geschäftsmodelle in der digitalen Ökonomie, Josef Eul Verlag, 2001.

[14]R. Wüstenhagen, J. Boehnke, Business models for sustainable energy, A. Tukker, M. Charter, C. Vezzoli, E. Sto, M.M. Andersen, System Innovation for Sustainability 1. Perspectives on Radical Changes to Sustainable, 2008, pp. 85-94.

[15] A. Osterwalder, Y. Pigneur, Business Model Generation, Modderman Druckwerk, 2009.

[16]L. Okkonen, N. Suhonen, Business models of heat entrepreneurship in Finland, Energy Policy 38, 2010, pp. 3443-3452.

[17]Gordijn, J. \& Akkermans, H. (2007): Business Models for distributed generation in a liberalized market environment. Electric Power Systems Research Vol. 77, Issue 9, July 2007, 1178-1188.

[18]K. M. Eisenhardt, M. E. Graebner, Theory Building from Cases: Opportunities and Challenges, Academy of Management Journal 50, 2007 (1), pp. 25-32.

[19]R. K. Yin, Applications of case study research, Sage Publications, 2003

[20] O. E. Williamson, Transaction-Cost Economics: The Governance of Contractual Relations, Journal of Law and Economics 22 (2), 1979, pp. 233-261. 